\title{
The footwear factory's assembly sector: opposing organizational structure and quality from the ergonomic work analysis
}

\author{
Kláudia M. M. N. Silva ${ }^{a, *}$, Bernardo G. P. Coelho ${ }^{b}$, Josemir V. S. Junior ${ }^{b}$, Luiz F. M. Faria ${ }^{b}$ Ludmila Dutra $^{b}$, \\ Marília Alvarenga ${ }^{b}$, Renan Roggini ${ }^{b}$ and Eliza Helena de Oliveira Echternach ${ }^{b}$ \\ ${ }^{a}$ Laboratório Integrado de Engenharia de Produção (LIPES), sala 3300, Production Engineering department, \\ Engeneeting School, Universidade Federal de Minas Gerais (UFMG), President Antonio Carlos Avenue 6627, \\ Univerrsity Campus, Pampulha. CEP 31.270.901, Belo Horizonte, Minas Gerais, Brazil \\ ${ }^{b}$ Production Engineering Department, Engineering School, Universidade Federal de Minas Gerais (UFMG), \\ President Antonio Carlos Avenue 6627, University Campus, Pampulha. CEP 31.270.901, Belo Horizonte, Minas \\ Gerais, Brazil.
}

\begin{abstract}
Data from 2006 indicated that Brazilian footwear leather industry was composed of approximately 9,488 formally registered establishments, considering the leather industry, footwear and leather goods. It was responsible for 211,582 people employed. However, in spite of having many employees, this kind of organization found several problems when analyzed from the ergonomics view. With this premise, then, in order to identify bottlenecks and other engineering problems that could cause discomfort and motivation lack among workers, leading directly to the loss of the product quality, the assembly sector of women's shoes factory was characterized.
\end{abstract}

Keywords:Taylorism/Fordism, Operacional Performance, Assembly Line

\section{Introduction}

From the observation of the work in the assembly sector of women's shoes factory, in Belo Horizonte, $\mathrm{MG}$, this paper aims to analyze, on the Ergonomic Work Analysis view (EWA), organizational elements in a Taylorist / Fordist type structure, issues that affect the operational performance conditions and, consequently, the final product quality.

Companies in the footwear industry are examples of assembly lines factories whose main characteristics are the fragmentation of activities and the imposition of the line speed to achieve a pre-established goal. This kind of organization could cause problems that affect the operator performance and even impact the product quality.
Thus, due to the excess of complaints about footwear's quality by the PV factory's consumers, we sought to compare the operational performance in the assembly line with the Taylorist / Fordist organization idea to ascertain how these factors could be directly associated with the lack of product quality.

\subsection{About the factory}

The factory, called PV, is in the women's footwear business since 1975. Its mission focuses on producing footwear with quality, design and comfort, aiming to anticipate fashion trends through research of international trends and technology.

$\mathrm{PV}$, under the coordination of a group of brothers, has 135 employees in various sectors, whose school degree is not only lower than or equal to high school

\footnotetext{
${ }^{*}$ Corresponding author: kakaunevessilva@gmail.com
} 
but also without or with low professional qualification. In this factory, beginners learn by participating of the products fabrication and by following the more experienced in the industry. The shoe production is on average 1200 pairs of shoes/day, extendable for a few hours depending on the demand and employees work 40 hours weekly. All employees receive an additional wage according to the extra time worked.

Since it is a women's shoes factory, the type of production varies according to the season and the fashion trend. The factory produces shoes, heeled sandals, undergrowth sandals and boots. The ideology of the production is "Just in Time", with minimum stock available for three days.

Most workers execute their function in a standing position to quicken the tramline manufacturing and facilitate the movement of the movement from one section to another. The daily goal to be achieved can generate a bonus for the section's workers, depending on the percentage of financial return in that period of time. Hence, as soon as the customer orders a product, the sectors of production planning (PCP) and material purchasing are informed to start the manufacturing process.

The main raw material used is leather. This material is provided by tannerys from São Paulo, Mato Grosso, Minas Gerais and the southern region of Brazil. The selection of the leather to be purchased is made in the stockroom and it is required the experience of the worker to identify which is the best type of leather for a given manufacturing. After the selection of the leather, it is the sewing and cutting sector's part of the process, and then the separation of inputs and finally the assembly sector.

The assembly sector is the place in which the production process ends. This is conducted from the line production's and the work fragmentation's perspective. For this reason, this sector was chosen for the EWA observations.

\subsection{Theoretical Framework}

Data from 2006 indicated that the Brazilian footwear leather chain was composed of approximately 9,488 formally registered establishments, considering the leather industry, footwear and leather goods. In the same year, only the Brazilian footwear industry consisted of 6,346 establishments and was responsible for 211,582 people in formal employment [1].

Many shoe companies in Brazil, as the one in this paper, use intensive work force with the simultaneous production of different goods, utilizing a handicraft process, but on a mass production model. The training occurs inside the job, called on the job training [4].

The factors related to non-efficient working conditions may be related to the workers' low qualification, the restriction of activities, an excessive division of work and an excessivelly limited productive system, limiting the worker performance to a single operation [1].

In ergonomic studies conducted in several footwear industries, it can be perceived that improvements in job places, infrastructure, and work environment are usually easily resolved. However, while during the process the ergonomic process can is able to identify organizational problems pertaining to the human management at work, several difficulties related to the culture that prioritizes the financial perspective can be detected [1].

For instance, according to Guimarães, the advances made by Japanese companies stimulated this business sector during the $80 \mathrm{~s}$ and $90 \mathrm{~s}$, researching for new concepts in relation to the services, processes and products quality ${ }^{1}$. However, it seems that the translation of the concepts originated from the Japanese automotive industry did not pass on to the footwear sector "gaucho" (from Rio Grande do Sul). Consequently, the foundations of the Toyota Production System were not assimilated. Besides, it was believed that the key to high productivity was mainly the work being performed in the standing posture, regardless of the multifunctionality which takes advantage of the dynamic posture [2].

Hence, summarizing the points cited, before Toyotism, the worker acted according to the Taylorist/Fordism ${ }^{2}$, in the same task and in a prolonged static posture. In other words, historically the sewing was done preferably in the sitting posture and on straw chairs. Yet, even with all the changes of current market, the situation remains the same, except for the sewing part of the process, which is still done preferentially in the standing posture. Nevertheless, during the theorical framework period, data corroborating

\footnotetext{
Quality means "doing things right," but things that need to make sure production vary with the type of operation. The performance operation quality leads to the satisfaction of external customers and it makes life easier for people involved in the operation. Satisfying internal customers can be as important as satisfying to external consumers [3].

2 The Taylorism / Fordism brings the idea of efficiency based on the division and subdivision of work, unyielding supervision, low qualification rates of the work of the line production. S(he) worked following a rhythm similar to that of a delicate machinery producing goods in a mass scale [2]
} 
the connection among organizational structure and operatory performance were not found. This suggests the need of more research articles on this field of study, since they could explicitate the relation of these elements with the intended quality of the products involved.

\section{Methodological Formulation}

The ergonomics is "a scientific discipline that deals with the understanding of interactions among human beings, other elements of a system; and also the profession that applies theory, principles, data and methods to projects in order to optimize human well being and overall system performance " (IEA, 2010).

The Ergonomic Work Analysis (EWA) combines observation techniques with description and validation procedures in order to corroborate the results of discussions, qualitative and quantitative questionnaires, interviews and group activities, aiming to allow self-confrontation through critical evaluations of the work positions.

Thus, the procedure adopted to analyze the targeted industry, the PV, consisted in seven (7) technical visits, divided into a year time frame, in the morning, with an average duration of $3 \mathrm{~h}$ each, according to the Ergonomic Work Analysis (EWA) viewpoint.

The first two visits were intended to generate an overview of the production process. In this context, some data was collected, such as the company's overall layout, its sectors, its clients, the manner of purchasing products, and even shoe models. Also, the posture of the workers during their activities was evaluated, direct interviews were done and questionnaires were given to the responsible for the management of the production and the production planning.

With these data, the assembly sector was chosen to be the focus of the analysis, since this is the last sector of the plant, which all other sectors' mistakes go there. Also, in this sector, the work is performed under the conditions of the assembly line. In fact, the aspect that drew the attention of the group for this site was an application by the PCP that requested a measurement of the time spent in each part of the line in order to optimize the process. These factors demonstrate the organization of work according to the Taylorist/Fordist.

The other five visits were in the assembly sector (see Figure 1), where a layout scheme was proposed, subdividing the tasks in nineteen sections. For each section interviews with workers, working time measurements and recordings and photography were realized. During these visits, there were simultaneous conversations with the manager of production, with the sector responsible for PCP and with those responsible for the warehouse and sales department.

At the end of the process, the responses of the operators were compared to their superiors' and to other data collected and the literature review. The intention was to group all the data and propose actions for the improvement of the factory.

A final visit was realized to validate the data.

\begin{tabular}{|c|c|c|c|c|c|c|}
\hline & Activity Deployment & $\begin{array}{c}\text { Visit } \\
1\end{array}$ & $\begin{array}{c}\text { Visit } \\
2\end{array}$ & $\begin{array}{c}\text { Visit } \\
3\end{array}$ & $\begin{array}{c}\text { Visit } \\
4\end{array}$ & $\begin{array}{c}\text { Visit } \\
5\end{array}$ \\
\hline $\begin{array}{l}\text { londition } \\
\text { for implementa } \\
\text { tion of } \\
\text { activities } \\
\end{array}$ & $\begin{array}{l}\text { Knowing the activities } \\
\text { prescribed in } \\
\text { each section of } \\
\text { the assembly industry }\end{array}$ & $\mathrm{X}$ & $\mathrm{X}$ & & & \\
\hline $\begin{array}{l}\text { condition } \\
\text { for implementa } \\
\text { tion of } \\
\text { activities }\end{array}$ & $\begin{array}{l}\text { Talking to the sector } \\
\text { of production plan- } \\
\text { ning to determine how } \\
\text { he makes the sche- } \\
\text { dule of daily activities }\end{array}$ & $\mathrm{x}$ & & & & \\
\hline $\begin{array}{l}\text { Tasks } \\
\text { Requirements }\end{array}$ & $\begin{array}{l}\text { Measur- } \\
\text { ing times of activities at } \\
\text { different times }\end{array}$ & $\mathrm{x}$ & $\mathrm{x}$ & $\mathrm{x}$ & $\mathrm{x}$ & \\
\hline $\begin{array}{l}\text { Process } \\
\text { Variability }\end{array}$ & $\begin{array}{l}\text { Analyze } \\
\text { the intermediary } \\
\text { sector is made to see } \\
\text { how the separation of } \\
\text { inputs }\end{array}$ & & $\mathrm{X}$ & & & \\
\hline \begin{tabular}{|l} 
Process \\
Variability
\end{tabular} & $\begin{array}{l}\text { Check the seasonali- } \\
\text { ty of production } \\
\text { compared to workers } \\
\text { in sections of thepur- } \\
\text { chasing departments of } \\
\text { factories }\end{array}$ & & & $\mathrm{X}$ & & \\
\hline \begin{tabular}{|l|} 
Regulatory \\
Mechanisms \\
\end{tabular} & $\begin{array}{l}\text { Bring out hidden } \\
\text { facts of the production }\end{array}$ & $\mathrm{X}$ & $\mathrm{X}$ & $\mathrm{X}$ & $\mathrm{X}$ & $\mathrm{X}$ \\
\hline $\begin{array}{l}\text { Productions } \\
\text { activities } \\
\text { validations }\end{array}$ & $\begin{array}{l}\text { Point out the problems } \\
\text { from viewpoints } \\
\text { of performance, quality } \\
\text { and health of workers }\end{array}$ & & & & & $\mathrm{x}$ \\
\hline
\end{tabular}

\section{Results and discussion}

\subsection{Defining the ergonomic demands:}

The PV sectors are: creation, modeling, programming, commercial section, purchasing, stockroom and production. The production is divided into four sections: cutting and sewing, intermediate, assembly and quality. The factory also possesses the maintenance and the dispatch sectors. Each sector has its responsible manager, whose function is to coordinate tasks and evaluate the service provided (see Figure 2). 


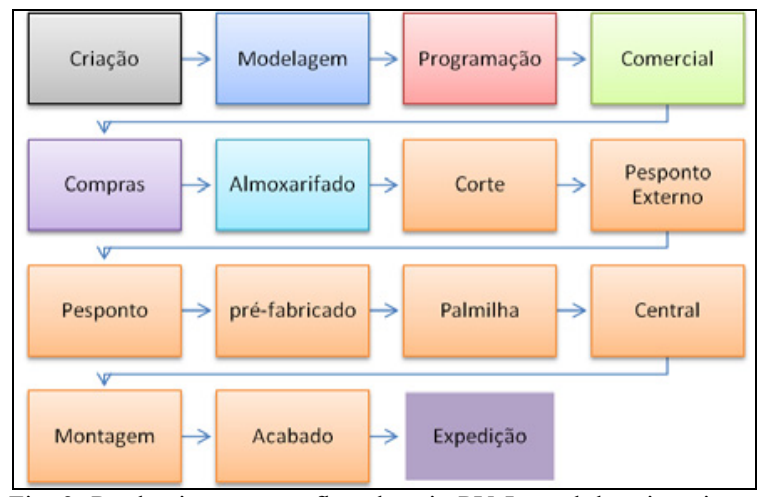

Fig. 2: Production process flowchart in PV In each box is written creation, modeling, programming, commercial, purchasing, warehouse, cutting, external stitching, stitching, prefabricated, insole, central, assembly, finishing and shipping respectively

From each factory sector: by research group observation, it was noted in the sewing industry that the tasks are divided in groups responsible for cutting, trimming, stitching, aligning, and also measuring the size, shape and silk of the company symbol. The work is quite repetitive. Almost all professionals, mostly women, stay in standing position throughout the workday. And there is a strong smell of raw materials (rubber and leather) caused by an inefficient air circulation and excessive machines' noises.

There is also a section between the sewing and the assembly sections. This section intends to allocate materials that need to be assembled in the correct order. It triggers the production control department (PCP) and, after, the manner the material distribution will be done to the assembly sector is organized.

The assembly sector has a conveyor belt (Figure 3) where the elements to mount the shoes are placed. The different assembly line manufacturing stages are: collage of the front, the middle and the back of the shoes, mold parts, fixing and removal of the excess of glue, sanding and finalization. Although there are many machines, the operators must be agile and alert. The conveyor belt assembly has a pre-set speed determined by the PCP sector, which that defines the daily goal too. If the goal is not achieved, overtime will be done to streamline the production. In this sector the psychological pressure seems higher than in others, due to the high propensity of delays and failures.

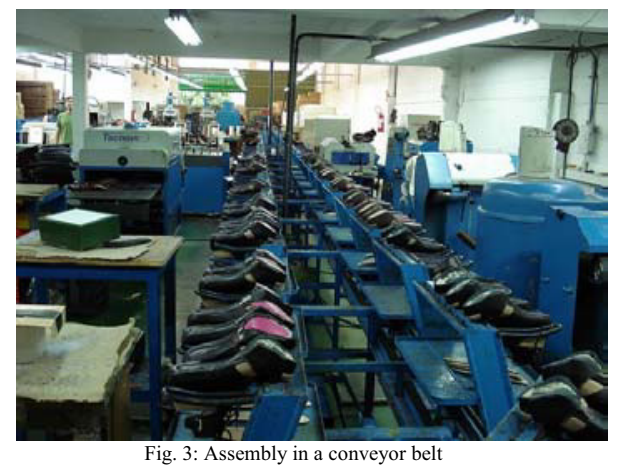

Thus, the ergonomic demand was: How the work organization impacts in operating performance, leading to problems involving the product quality and, therefore, delays and customer dissatisfactions?

\subsection{Shoes assembly sector}

\subsubsection{Characterization}

The assembly is characterized by having a warehouse, a PCP and two rotatory conveyor belts shoes' sole preparation and assembly. The assembly conveyor belt is the company's "heart", because it is where the shoes are assembled. This conveyor belt is divided into 18 sections arranged in an oval layout, as shown in Figure 4.

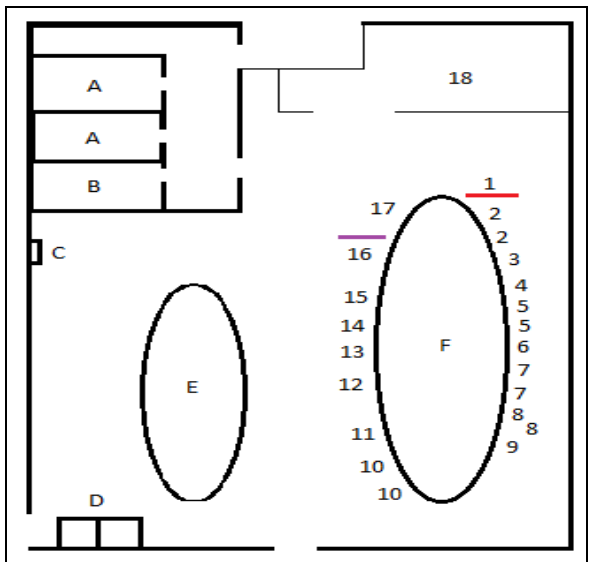

Fig. 4: Assembly sector layout. Prepared by the research group. Legend: A - Warehouse, B- PCP, C- Hit point, D- Bathroom and water fountain, E- Conveyor belt (preparation), F- Conveyor belt , 1 - Assembly beginning, 2 - Formation, 3 - Gluing, 4 - Plait in the mold, 5 - Nozzle sharpening, 6 - Plait in the mold, 7 - Glue fixation, 8 - Adjusts the shoe front, 9 - Sanding the bottom, 10 - Gluing, 11 - Makes the boxes and separates shoe and sole, 12 - Glues the shoe's sole, 13 - Adjustment of the sole width and gluing, 14 Final appearance of the shoe, 15 - Final appearance of the shoe, 16 - Revision, 17 - Finalization 18 - Shipment. 


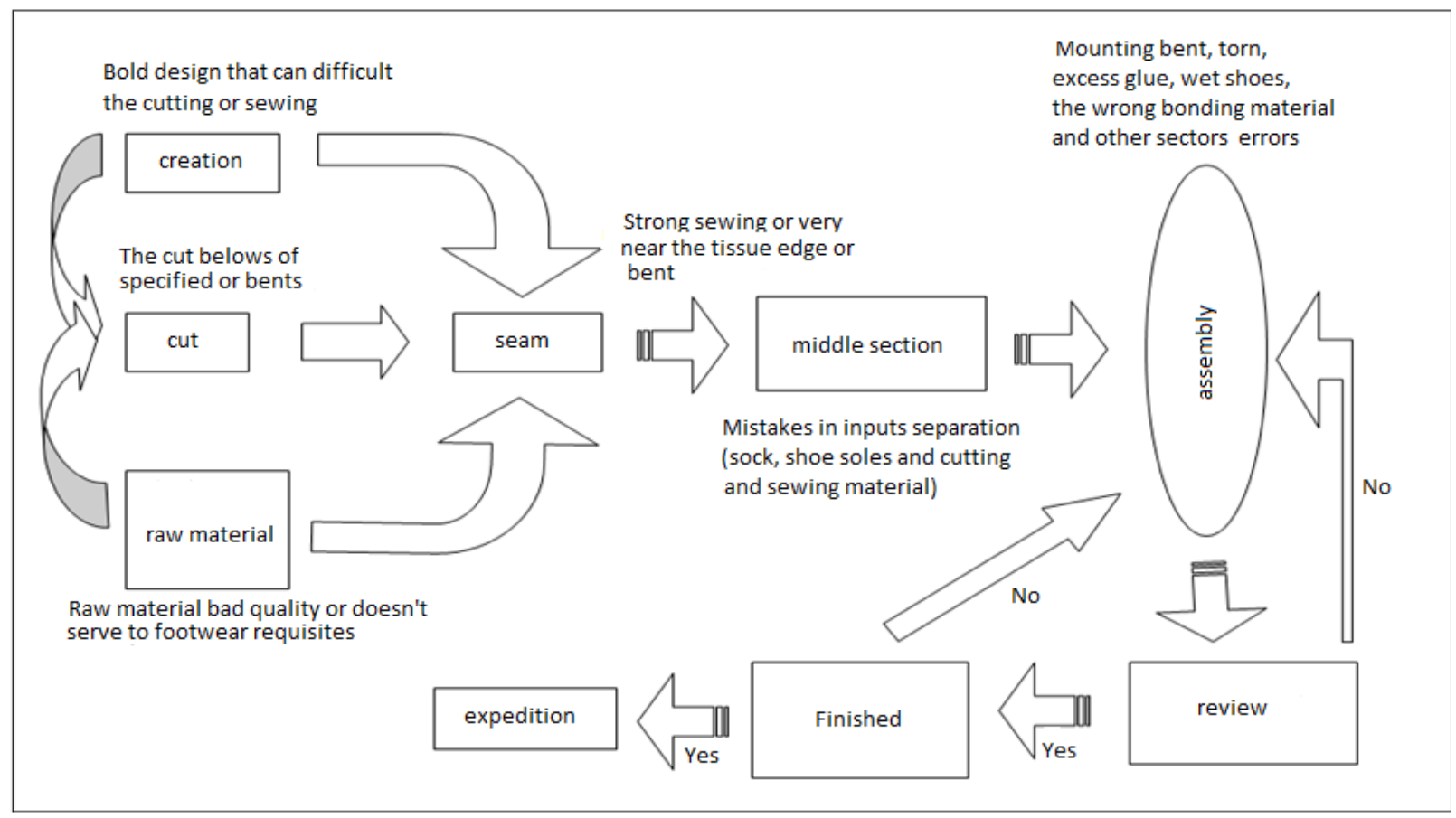

Fig. 5: Previous sections error propagation

The conveyor belt speed ( 1 hour for boots and shoes and 1:20 hours for sandals) determines the rate of production. It is controlled according to the daily goal, stipulated by the sector of the PCP. Different types and models are assembled at the same time, according to the production order (PO - see Figure 6), this requires from the employees to constantly adjust themselves to the process.

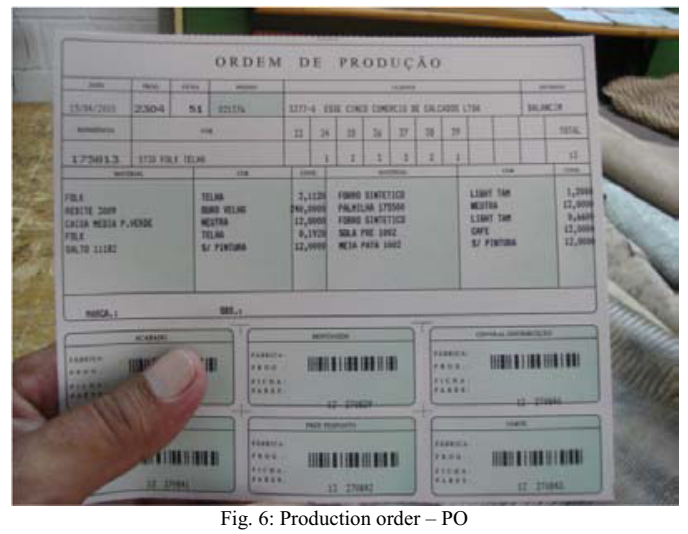

Incidents like broken machines, sick employees, delay in materials delivery, among others, also influence the production speed and the group's selfregulation to meet the daily targets (1000 - 1200 pairs/day). Consequently, there is an increased work- load in the product review sectors due to the fast rhythm of the employees, who tend to make more mistakes, harming the footwear quality.

\subsubsection{Pre-diagnosis}

The pre-diagnosis raised indicated that problems associated with the conveyor belt excessive speed, the lack of communication between sections and command and the propagation of previous sections' errors (see Figure 5) increase the employees workload, requiring increased awareness and selfregulation, cognitive and physical effort, leading to lack of work motivation and increased delays, as well as the loss of final product quality.

\subsubsection{Description of the problems}

Raw Material: The responsible people for the programming, the warehouse, the purchasing and the marketing sector were contacted to verify the issue of the lack of quality of the raw materials for manufacturing. It was reported that the raw material's source is some factories known suppliers, and if the specific product is not right, they return the leather and send a template showing how the raw material should be. The evaluation of the material that arrives to the factory depends on the warehouse employee's tacit knowledge. He, by touching it, decides if the received material is good or bad for the production. According to his evaluation, all the material that arrives is ready 
to be processed, however, for the assembly sector, it not when this data went to the assembly workers, they disagreed. The assembly sector goes unsatisfied with material quality. Frequently, the leather arrives with the incorrect specification (too hard or too soft) and they must work with the material received. This takes time, harming the whole production. Other problems reported are stains and scratches on the leather, which affects final appearance of the footwear produced.

Working activity: In regard to work, it was reported that a very small number of effective workers corrupts the efficiency of the footwear production. Another observation from the managers was that the complete shoemaker training course offered by SENAI is not sufficiently. Thus, the contracted employee is quickly trained at the factory and learns their craft in practice - on the job training.

Measurement of activities time: the PCP suggestion was that measurement time would reduce the workload because they could measure the time spent in each step, avoiding waste of time and increasing the productivity (thought Taylor).

Equipment: Some machines are old, but they work. There are newer machines, but they are used only when there is an excess of demand - their use during low demand means "investing" time and effort to swap them and, since they are very heavy, the idea became impractical. For the owners and managers, the biggest assembly problem is the support system and maintenance, as the machine is very heavy, it is difficult to transport them. And stopping a machine means a loss of production time.

Review: The review of inputs and shoes are inefficient. Without appropriate machinery and the lack of professional preparation, it was realized that the shoes go to many customers with quality problems. The managers tried to implement a production quality sheet (see Figure 7) that worked for a short time, because, according to them, either the staff did not know how to work with this in the right way or there was not time enough to direct attention to this.

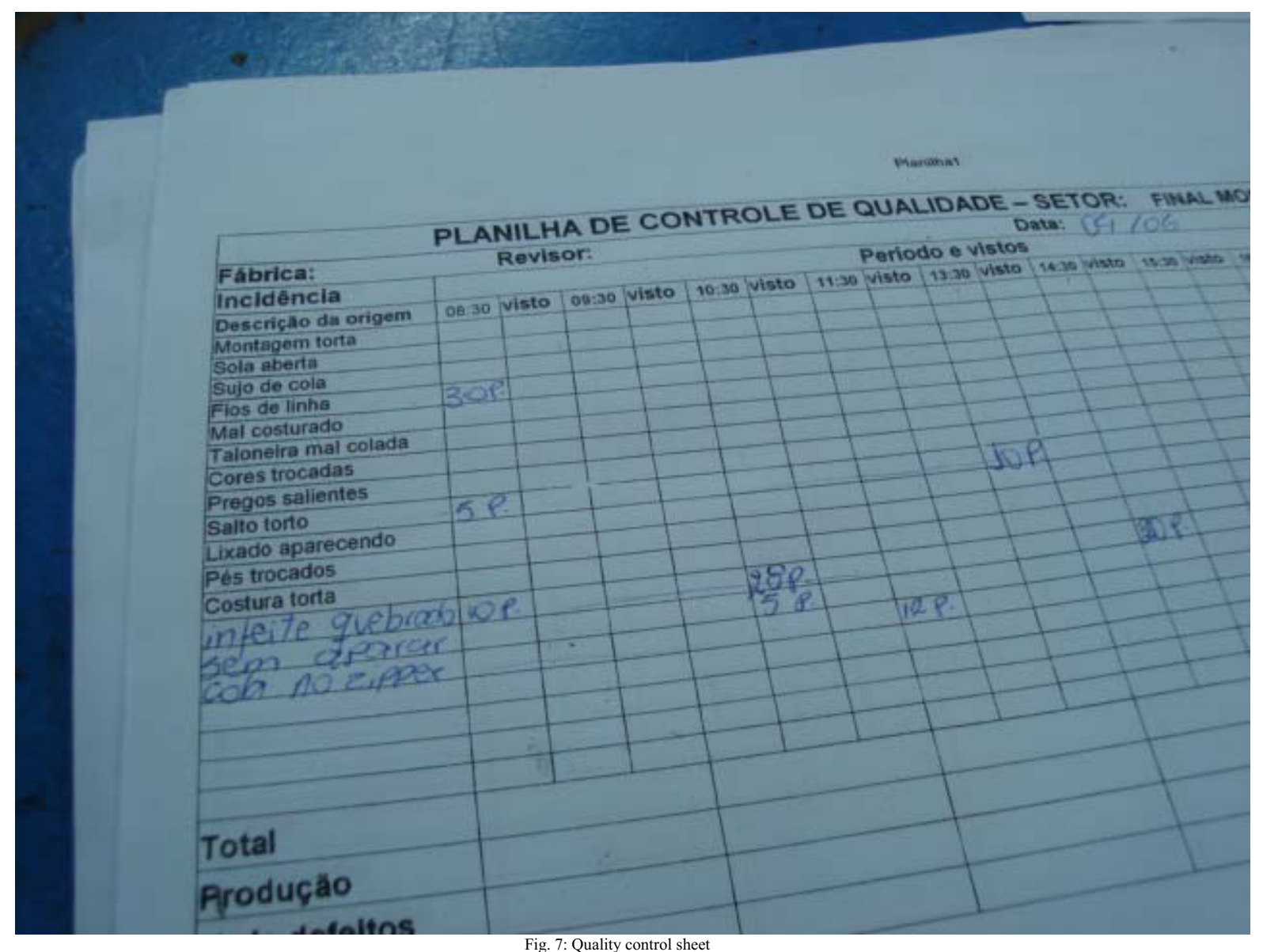


Customer's Service (SAC): Data provided by the factory showed 138 refunds for client companies, a total of 1360 pairs, causing a financial loss of more than 70,000 Reais on September 2010. Even after the return of the goods, there was not a control program of what came back. There is no information about which batch the returned footwear belonged to, the reason for returning them, or the criteria adopted for that. The marketing affirmed that the client simply calls, sends the shoe back and says that it is not good. Thus, they only account for what was returned, the amount of money and how much harm was done.

Demotivation: During the penultimate visit in PV, it was noticed that it was decided to change their production in this way: some employees were relocated, others were gratified for increased productivity. However, the worker in the assembly sector did not noted any changes. They continued with the same complaints and very discouraged with their service.

Absenteeism: In the penultimate visit, the responsible for PCP reported that the factory was suffering with excessive absenteeism. The main cause was that most workers were women and mothers should take care of their children.

Work multifunctionality and overtime: Another problem was the low quantity of employees. There were extremely few to produce the desired goal, so when a particular sector is into arrears, some workers are forced to move to another sector or section. This brings problems to the assembly sector. Also, this increases the propagation of errors because the staff need to do their service and should work in other positions when needed, making the job even more exhausting. When the employees still do not meet the goal (1000 to 1200 shoes pairs/day), they should work overtime on Saturdays and/or one extra hour after work every day until they achieve the goal.

\subsubsection{Assumptions:}

It was found two-fold:

"The lack of indicators can raise difficulties on the visualization of the production process by the employees, favoring the mechanical work and loss of professional identity. This creates demotivation and, therefore, delays and decreases the quality of the final product".

"The absence of a professional responsible for analysing the mistakes that impact in product quality" The lack of quality standards required by the shoe factory, related to appearance, comfort and technical specifications - such as: sewing in place, material securely fastened on the shoe's sole, resistance reaches the factory with respect to financial returns, generating loss and workers' and customer's dissatisfaction.

\subsection{Good actions}

Given the findings about the problems, the following actions were proposed:

The establishment of indicators to evaluate the job and the quality problems. This picture should be exposed for everyone to assess their performance and self-motivation to work. The indicators should point to: the amount produced in each sector, points that require special attention, the main problems faced during the production process, problems of communication between sectors and neighboring sections and review of the materials that arrive to the assembly sector.

To put a professional to gather data concerning the most frequent errors in production. Data collected for statistical treatment.

Placing a picture that shows all the stages of the production process of the shoe model, so the professionals will be able to locate themselves and recognize the importance of their work in the company.

A program to locate the returned batch, uncovering the reason for the returns, providing the quality control of the product according to the customers desires (the company has the program, but due to a lack of time and professional organization, they do not utilize the data).

\subsection{Proposed actions validations}

The proposals were received by the factory. However, when addressing the personnel allocation for other activities, the ideas have been rejected. They argued, since the employees work in their limits and cannot find more opportunities in the job market, the workers should be helping in the production of footwear manufacturing.

Thus, according to PV, it was found that the proposed actions are effective only for a long term. And that, if the professionals work in the assembly sector was eased, generating motivation and work performance improvement it would be impossible to realize these things in that year. 


\section{Conclusion}

\subsection{Summary of the main data obtained}

During the period of observations, the following problems were verified: difficulties while dealing with the raw material used; difficulties with the input division; conveyor belt velocity superior to the work capacity; excess of extra hours; propagation of errors through sectors and sections; production logic ("just in time") incoherent with the number of workers; shortage of equipment; decreasing of the quantity of costumers due to problems in the product quality; negative revision of the final product; a great amount of footwear's variability circulating in the same production line and with the same conveyor belt velocity (greater quantity of errors derived from the modern designs); excess of absenteeism and the inequality of wages (leading to the workers' demotivation); excessive work hours in different sectors or sections to compensate for an exaggerate demand or the lack of work force; lack of errors indicators where the critical points are identifiable.

It was also observed that most workers worked in a repetitive and fragmented rhythm in an uncomfortable standing position (doing lumbar flexions) for the whole working shift. Lastly, there is the deficiency of air circulation, which keeps the odor of glue and leather in the same space, impregnating the site and risking the physical health of the employers.

\subsection{Final Considerations}

It can be inferred that a Taylorist / Fordist work organization implies in a highly specialized and divided type of work, in which the workers are obliged to work by the same rhythm as the assembly line (1 hour for boots and shoes and 1:20h for sandals). This causes physical and cognitive overload in the works in the assembly's sector and influences directly in the quality of the final product, the footwear. Data from PV's sales department have shown that the number of customers has been decreasing while the quantity of complaints in the customer's service has increased. For instance, on September 2010 there were over 1000 pairs of footwear which were returned.

Therefore, confirming what the studies concerning the Brazilian footwear's industry (mostly based on the Taylorist / Fordist production system) affirm, it was perceived that the productive process of the evaluated factory is not adequate to the workers' opera- tory comfort. Moreover, the error propagation from the sectors summed up with the work overload and the process variability cause direct losses in the final product's quality, creating dissatisfaction in the clients.

\section{References}

[1]. J. Renner, P. A. Oliveira and L. Guimarães, A ergonomia como um fator de transformação na cultura organizacional: um caso da indústria calçadista do RGS in ABERGO Journal. Curitiba, Oct. $29^{\text {st }}-$ Nov $02^{\text {st }}, 2006$.

[2]. L. Guimarães and J. Renner, A questão da postura de trabalho no setor da costura da indústria calçadista, in ENEGEP Journal - Ouro Preto, MG. Oct. $21-24^{\text {st }}, 2003$.

[3]. N. Slack, S. Chambers, C. Harland, A. Harrison and R. Johnston, Administração da Produção. Atlas S. A. ed. São Paulo, 1997, pp 71.

[4]. R. Cornelli and L. B. M. Guimarães, Redução de perdas de matérias-primas e de custos humanos utilizando a análise macroergonômica do trabalho no setor de componentes de calçados. Pos-graduate program in production engineering, Porto Alegre, RS, 2008. 